\title{
Study on Unity between Translation Industry Demand for Talent and Transition Reform of English Professional Integration
}

\author{
Jie Ding ${ }^{1, a}$ \\ ${ }^{1}$ Jilin Agricultural Science and Technology University, Jilin 132101, China. \\ a Jie_ding001@126.com
}

Keywords: Translation talent, English majors, teaching reform.

\begin{abstract}
Translation teaching for English majors is teaching and practicing activities which aim to develop the students' translation competence. Then it is the problems in Translation Teaching for Undergraduate English majors is that the positioning of translation teaching is not scientific. So it is necessary to make a scientific positioning of translation teaching by reform comprehensively in Teaching materials, teaching methods, teaching methods, assessment indicators, incentives, faculty building.
\end{abstract}

\section{Introduction}

With the deepening of reform and opening up, China's social politics, economy, culture, science and technology has made rapid development, foreign political, economic, cultural and technological exchanges become more frequent. Social demand for translators is growing, increasingly demanding. In China, every year out of the culture of qualified translators, particularly the contradictory demands of society and the number of high-level translators between the increasingly prominent. In 2000, for example, the national college entrance examination of the College Freshmen 2.2 million (1.13 million undergraduate, specialist 1.07 million), of which, 17 million people in Western newborn, according to 95 percent graduation rate, 2003-2004 of approximately 161,000 Western graduates enter the job market, which foreign language graduates, received a number of specialized training in translation is not more than 50, 000 people, which is 50, 000 people there are some people for various reasons do not or can not be engaged in translation work. Such translation Talents of social development can not meet the needs of all levels of translators. The culture translators translate important teaching positions have to bear an inescapable responsibility. Due to historical reasons, the translation teaching in China and there are still many drawbacks witch needs reform factors, and the social development needs of translation professionals in stark contrast. Therefore, the study of the development and reform of translation teaching, translation teaching discuss practical problems exist, to find meaning solution to the problem is very important.

The 21st century is the information age, the information society on translation teaching has brought opportunities and challenges. First, the information society there is a conflict with the traditional translation belief mass of information; secondly, translate object in the information society has changed. Third, highly developed information technology has changed the traditional mode of translation; fourth, half a century after the development of machine translation, has made great progress; fifth, the Internet being affects a large field of teaching change, the article by analyzing the impact of the information society and the Internet to bring translation teaching, and explore the opportunities and challenges of information technology on the reform and development of traditional translation teaching brought.

\section{Several Theoretical Problems of Translation Teaching}

Different people have different views on this issue. Different views will produce different translation methods and strategies, but also on what the problem is translation teaching come to different conclusions. Throughout the history of translation studies, we can see many linguists and translation theorists have tried to set out a complete translation under the definition from a macro 
point of view: "Translation is a work in language operate, which uses a languages text to replace the text in another language in the process of translation is the product of a speech language while keeping content, that is, the sense of constant change to another language speech product of the process. "translation is looking for acceptance and primitive language information as close as possible, the natural peer discourse, starting with the sense of like, followed by on style and so on. "Translation and Language Behavior choice but closely related to the special way to Interlingua information transfer." Translation is a cross-cultural exchange of information and exchange activities, its essence is spread. As many definitions, which is more accurate and appropriate? To answer this question, let's look at translation itself.

Many specific forms of translation, with interpretation, translation, machine translation, translation from the physical form, its performance for the selection of a combination of various types of zymology, concrete can be divided into four categories: (1) sound language symbols, namely natural verbal language, which took the form of telephone communications, internal and external negotiations and receiving foreign dignitaries, etc; (2) the silent language of symbols, text symbols including symbols and images, its manifestations negotiations resolution, social letters, messages, and a variety of communications printed literary works; (3) sound non-verbal symbols, namely the dissemination process so-called sound without distinction syllable "language" symbol, the common way: special rereading of voice, tone change, laughter and applause, such symbols can be divided into syllables no specific semantics is not fixed, the information is in some locales to spread, such as laughter may be loaded with positive information, may also be loaded with negative information, and if applause can spread welcome, favor, happy and other information can also be passed a polite denial, etc.. (4) the silent non-verbal symbols, namely a variety of human language symbols, showing human movements, facial expressions and clothing, and other accompanying silent language symbols, such symbols have distinctive national culture, such as some human action, in a different national culture semantic information represented in a completely different, not only that, it can also strengthen the sound language dissemination of results, such as when talking, if accompanied by appropriate body language, will significantly enhance the expression of the effect of spoken language. These four categories can be expressed both symbol translation of the original code, can also express the translated coding, i.e. they can be used alone as a material carrier of the original code or decoding can also be composed of two, three, four together constitute Translation carrier code or native code.

From an operational point of view the program, including understanding the actual translation, transformation, expression of the three links, understanding that the original code analysis, accurately grasp the information expressed by the original code; conversion is to use a variety of methods, such as in the form of interpretation or translation of each Select the class system using symbols, combinations, extended, translation skills such as concentration and so on, the original code information is converted into the equivalent expressed by decoding the information; expression is a new language system accurately expressed. Translation form and content of such complicated, from abstract definition of a philosophical level translation is having a very difficult task, many scholars at home and abroad have made many efforts to this, eyes of the beholder, the wise see wisdom from different angle to make a translation summary and conclusion.

\section{Situation of Translation Teaching}

China's vast territory, running around the characteristics of colleges and universities vary greatly, regardless of translation teaching vastly different from the form or content. In this case, the current situation of translation teaching in our large-scale surveys and studies are unrealistic. However, the existing survey results analysis, synthesis, and form their own opinions and reflections on this basis, it is also very meaningful work.

Translation untrained teachers teaching through formal translation. Most teachers have neither been systematic study of translation theory, the practice has not received specialized training, used materials began scripted. The result can only be translated into English and Chinese Sentence Lesson 
contrast, or simply Intensive Course, students can only learn a few words or phrases, but most also know a few useless translation skills Bale.

Translation teaching programs and material selection is arbitrary. Translation teaching plan various colleges and universities very general, the extent to which students should simply summarize, no detailed discussion, so any teacher can understand and play, the plan can not really play its guiding role. In fact, even chaotic than planned translation materials selection and use. Western Department investigation involving more than a dozen have undergraduate foreign language, are taught at the high school stage translation course, you can use the same textbooks is difficult to find two schools, schools basically use their own written materials or handouts, this, of course you can play to the strengths of the school, highlighting its training objectives. But the underlying problem is that this will inevitably lead to confusion throughout the translation teaching, it is difficult to grasp the development of translation teaching as a whole. Also, do not rule out their own teaching materials prepared by the arbitrariness, the lack of market-oriented and science, and many other aspects of tendencies.

Translation teaching purpose is not clear. Most translation Teachers are looking to translate classroom as much as possible to teach students the theory of translation, translation methods and techniques to students immediately after graduation can be engaged in translation work. Such a desire is good, but we should be clear that the purpose of translation teaching is to make students understand the translation, translation understanding, have basic translation theory, lay the foundation for future development. May be present, because the purpose is not clear, culture methods dislocation occurs, it is translated as a training class and started a lot of translation exercises, there is no doubt that during the training, engage in intensive works to translate beginner students have become quite see experience and theoretical knowledge of the translators.

Students attitude is not clear. Students are "taught without translation" and influence the comprehensive English teaching mode, expect to have some lessons from the translation of the word translation, master a few tricks, you can "perform on stage," They teach teacher translation process, the relationship between standards and principles as well as the original, the translator and translation between the little interest that they want out of the classroom is downright translation translator. Students quick success will inevitably affect the teacher's teaching methods and attitudes.

\section{Measures and proposals Translation Teaching Reform}

To translate the teaching reform, we should clarify the status of translation teaching, role and significance. Almost all teachers agree that the translation, the translation course is to develop an important part of foreign language talents, foreign language teaching is essential, and one of the most advanced courses, foreign language students is an important means of several skills, with a very high practical value, role and significance are very important, but the awareness of translation teaching and translation of knowledge teaching reform still to be improved. Today, there are still quite a few people lack the awareness of the importance of translation teaching.

Translation teaching on the main issues that exist, the author believes that the key problem is that we lack a correct understanding of the discipline of translation and localization, lack of scientific discipline plan. To translate the teaching reform, the first thing is to translate discipline as an independent discipline to be building. The establishment of professional translation, to be scientific orientation of the training goal, so that the guiding ideology of teaching establishment, the curriculum, the reform of teaching methods, teaching team building and teaching culture has a basic starting point. Once established translation relatively independent disciplinary status, our translation teaching it is possible to get rid of the shackles of Applied Linguistics at present difficult to expand the embarrassing situation, move in the direction of scientific and systematic. We are pleased to see several generations of scholars translate academic efforts and academic achievements have laid a solid foundation for China's cause of Translation Studies, Translation Studies as an independent discipline was no longer a distant dream. 
In the practice of translation teaching, we see both the translated materials, or translate content and methods of teaching, often in the "technical" level to start teaching the most specific translation skills. However, it should be appreciated that translation is not just a simple language conversion activity, specific translation methods using a variety of factors affected the language, culture, society, ideology, age, etc., and therefore understand the translation from theory What, why translate, how to translate for the students to further understand the effective translation methods instructive. Therefore, we must pay attention to "technical" aspects of teaching, but also pay attention to the "Road", the level of doubts, in fact, certain teaching methods should be the product of a certain theoretical guidance, review of language teaching, whether it is translation approach, situational approach, communicative approach, functional approach, both in the corresponding language deployment theoretical guidance. We translate teaching, if not translated guidance of the theory, it is likely to fall into any teaching situation blind.

Existing syllabus, it has been used for 20 years. Now the quality of young people are quite different 20 years ago, the social, economic and cultural environment has greatly changed, the original goal of teaching has been unable to adapt to the new situation, therefore, it should be on the basis of in-depth investigation and study, to find the inadequacies of the existing syllabus, as well as the new situation requires new translation teaching, translation teaching syllabus revision as soon as possible. Under the new framework, combined with the results of the new theory of translation, organization of human rewrite requirements of the times Translation Textbooks.

\section{Summary}

This article discusses the following aspects of translation teaching reform proposed ideas and measures: 1) Deepening translation teaching; 2) to explore the translation of student-centered teaching mode; 3) increase the content of practical teaching style translation; 4) prepared in accordance with requirements of the times translation of materials; 5) improve the quality of translation teachers; 6) to improve the efficiency of translation teaching; 7) to improve the conditions of translation teaching.

\section{References}

[1] Chen Fukang Chinese Translation Theory History of Shanghai: Shanghai Foreign Language Education Press, 2000.

[2] Lu Jun, Chinese Translation Course Houxiang Qun Shanghai: Shanghai Foreign Language Education Press, 2000.

[3] Li Bingde, Li Dingren pedagogy Beijing: People's Education Press, 1991.

[4] Lusi Yuan, Qi-gold. 21th Century Translation Teaching and Research. Chinese translation, 2000 (1).

[5] Murray Translation Teaching: an important part of Translation Science - Starting from the basic concept of Translation Teaching and Research. Chinese Translation, 2004 (4).

[6] Zhang Mei Fong. On two different levels of translation teaching fields. Foreign language teaching, 2001 (5).

[7] Shi recipe teaching theory - based teaching, principles and issues. Beijing: Education Science of Society, 1996.

[8] Wen jun Translation Teaching of Foreign Languages, 2004 (3). 